for the measurement of productivity in scientific research. Although the institute is autonomous in the sense that it is not a member of any of the schools of the university, its policy will be determined by a committee whose chairman is Dr. Grayson Kirk, the president of the university, and whose members include Professor Edward W. Barrett (journalism), Professor A. F. Cournand (medicine), Professor William T. R. Fox (international relations), Professor M. D. Hassialis (mining) and Professor I. I. Rabi (physics). The institute plans to use the endowment from the Sloan Foundation as a regular budget, and hopes to finance research projects by grants from other sources.

\section{Fewer Students Teach}

THe attempt at an employment census for graduates from British universities which is carried out by the University Grants Committee (First Employment of University Graduates, 1964-65, H.M.S.O., 5s. 6d.) confirms the impression gathered by the Swann Committee that the tendency is for science graduates to stay on at universities for research. In 1964-65, 28 per cent of all science and technology graduates continued in research, compared with 26 per cent in the previous year. This is in line with the particularly rapid increase of the postgraduate part of the university population in the past two decades. The University Grants Committee has also found an increase of the proportion of first graduates going directly into employment. Of the men graduates taking jobs outside education immediately after graduation, 69 per cent went into industry; in 1963-64 the corresponding proportion was 66 per cent. At the same time the proportion of first graduates taking special courses for teacher training decreased from 18 per cent to 16 per centa signal that the attractiveness of the teaching profession in Britain is not yet great enough for the schools to be able to hold their own with industry and research in the competition for new graduates.

\section{No Aircraft Noise}

The Board of Trade, now responsible for civil aviation in Britain, has been moved to call an International Conference on the Reduction of Noise and Disturbance Caused by Civil Aircraft. Delegates from 24 countries and 9 international organizations met in London on November 22 and heard Mr. Roy Mason, Minister of State at the Board of Trade, say that the conference was not to discuss whether a noise problem exists but how it can be solved. "We accept that the problem exists and is very serious and that, unless adequate measures are taken, the amount of annoyance inflicted by aircraft will considerably increase in the coming years."

The conference was technical in character. One of its six committees was concerned with how the maximum permitted noise level could be defined, and the others with means of reducing particular sources of nuisance. Issues such as the intelligent siting of airfields, improving operational procedures, and insulating houses arainst noise are all relevant. The first possibilitv is irrelevant to airfields like London Airport and the John F. Kennedy Airport in New York, which can hardly be moved; the second is likely only to produce small reductions of noise; and the third savours of defeatism.
Speakers agreed that the real need is to reduce noise at its source, simply by building quieter aircraft. In the United States, it has been suggested that aircraft should be licensed for commercial operation only if they conform to certain standards of noise. This would force designers to regard noise as an important design parameter. There seems no prospect of unilateral action by the United States, however, for this would merely penalize aircraft using United States airfields, with a disastrous effect on commerce. What is needed is to define the minimum noise level which would enable airlines to continue economic operation and to gain international acceptance for this noise level. Reductions could then be made in this noise level as new aircraft come into use. To many this seems an unduly optimistic target, particularly with supersonic aircraft such as Concord only a few years away.

\section{Scientific Instruments}

THE exhibition of scientific instruments which has been on display at the Design Centre in London since October 5 has been such a success that it was extended by two weeks and will close today, December 3 . It is estimated that about 40 per cent of the visitors to the Design Centre since October 5, or more than 40,000 people altogether, have been concerned with the instruments. The modern scientific instrument tends to be faceless or at least stereotyped-beauty is in the eye of the user. But the Design Centre arranged the instruments with its accustomed style, and the exhibition was attractive as well as instructive. The instruments were described both by a brief simple description and by a longer technical one; it says much for the attractive typography at the exhibition that members of the general public have been reading both.

The instruments were selected by a joint committee from the Design Centre, the Scientific Instrument Manufacturers Association, and the Scientific Instrument Manufacturing Research Association. The criteria were reliability, accuracy, ease of use and appearance-not necessarily in that order. But one problem is to decide where ergonomics ends and aesthetics begins. The appearance of an instrument may well be a function of the other criteria which the committee considered. Size, shape and layout may be determined entirely by engineering considerations, although that is not always certain; but the shape of the knobs on an instrument, or its height from the floor and its colour, are matters for the ergonomist.

In any event, the exhibition has gone well, and the Scientific Instrument Manufacturers Association, which believes that British instruments are now as well designed as any in the world, is hoping for a rush of orders.

\section{Libraries a Disgrace}

The state of the libraries at British universities is alarming. This is one of the conclusions of the committee under Mr. R. Shackleton, now Bodley's librarian, which has investigated the libraries of the University of Oxford. The report of the committee (Clarendon Press, 15s.) shows that the libraries of universities in the United States are far ahead both in the total number of books they hold and the rate at which they are acquiring new ones. Between 1963 and 1964 the 